\title{
AMMONIA BASE NANOFLUID AS A COOLANT FOR ELECTRONIC CHIPS AHMED MOHAMMED ADHAM
}

Mechanical and Energy Engineering Techniques Department, Erbil Technical Engineering College,

Erbil Polytechnic University, Erbil, Iraqi Kurdistan, (Iraq)

\begin{abstract}
In this paper, the cooling performance of a refrigerant base nanofluid to cool down electronic chips was reported. An alternative base fluid $\left(\mathrm{NH}_{3}\right)$ is used to substitute the common known base fluid $\left(\mathrm{H}_{2} \mathrm{O}\right)$ to enhance the cooling capabilities of the nanofluid. $\mathrm{Al}_{2} \mathrm{O}_{3}-\mathrm{NH}_{3}$ with three different volume fractions $1 \%$, $3 \%$ and $5 \%$ ) was examined. To analyze the problem, two objective functions namely, the thermal resistance and pumping power, and the Strength Parteo Evolutionary Algorithm (SPEA2) was used to optimize the thermal and hydrodynamic performances of the microchannel heat sink. The ammonia-base nanofluid $\left(\mathrm{Al}_{2} \mathrm{O}_{3}-\mathrm{NH}_{3}\right)$ outperformed other coolants $\left(\mathrm{SiC}_{-} \mathrm{H}_{2} \mathrm{O}, \mathrm{TiO}_{2}-\mathrm{H}_{2} \mathrm{O}, \mathrm{H}_{2} \mathrm{O}\right.$ and $\mathrm{Al}_{2} \mathrm{O}_{3}-$ $\mathrm{H}_{2} \mathrm{O}$ ) in pumping power demand (0.144, 0.702, 0.724, 0.94 and $1.015 \mathrm{~W}$ for $\mathrm{Al}_{2} \mathrm{O}_{3}-\mathrm{NH}_{3}, \mathrm{SiC}_{-} \mathrm{H}_{2} \mathrm{O}, \mathrm{TiO}_{2}-\mathrm{H}_{2} \mathrm{O}, \mathrm{H}_{2} \mathrm{O}$ and $\mathrm{Al}_{2} \mathrm{O}_{3}-\mathrm{H}_{2} \mathrm{O}$, respectively) Under the same conditions. Furthermore, lightest microchannel heat sink was needed when the ammonia base nanofluid is employed. Finally, the key results from this study open the door for the possibility of considering this coolant for excessive heat producer electronic chips.

KEYWORDS: Microchannel, Nanofluid, Ammonia \& SPEA2
\end{abstract}

Received: Feb 07, 2019; Accepted: Feb 27, 2019; Published: Apr 30, 2019; Paper Id.: IJMPERDJUN201960

NOMENCLATURE

Cp Specific heat, $\mathrm{J} / \mathrm{kg}-\mathrm{K}$

$D_{h} \quad$ Hydraulic diameter, $\mathrm{m}$

f Friction factor

$H \quad$ Heat sink height, $\mathrm{m}$

G Volumetric flow rate, $\mathrm{m}^{3} / \mathrm{s}$

$H_{c} \quad$ Channel height, $\mathrm{m}$

$h_{a v} \quad$ Heat transfer coefficient, $\mathrm{W} / \mathrm{m}^{2}-\mathrm{K}$

$k \quad$ Thermal conductivity, $\mathrm{W} / \mathrm{m}-\mathrm{K}$

$n \quad$ Spherical particle parameter

$\Delta p \quad$ Pressure drop, $\mathrm{kPa}$

Re Reynolds number

$R \quad$ Thermal resistance, $\mathrm{K} / \mathrm{W}$ 


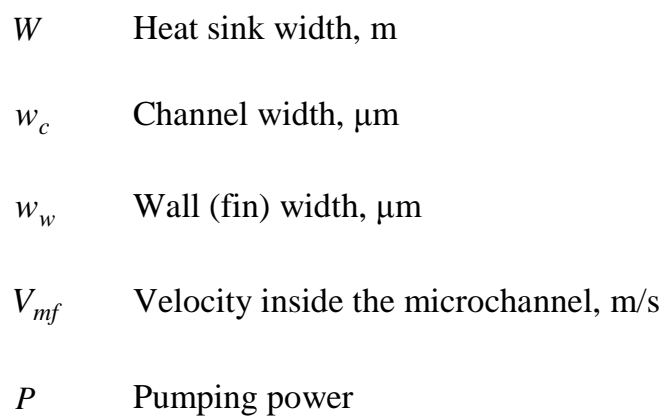

\section{Greek Symbols}

$\begin{array}{ll}\alpha & \text { Channel aspect ratio } \\ \beta & \text { Wall width to channel width ratio } \\ \rho & \text { Density, } \mathrm{kg} / \mathrm{m}^{3} \\ \mu & \text { Viscosity, } \mathrm{kg} / \mathrm{m}-\mathrm{s} \\ \eta & \text { Fin efficiency } \\ \phi & \text { Particle volume fraction }(\%)\end{array}$

\section{Subscripts}

$\begin{array}{ll}c & \text { Channel } \\ f & \text { Fluid (coolant) } \\ h s & \text { Heat sink } \\ n f & \text { Nanofluid } \\ p & \text { Particle } \\ w & \text { Wall }\end{array}$

\section{INTRODUCTION}

The large scale production of the Very Large Scale Integrated Circuits (VLSICs) in the mid-1970s, has resulted in a huge advance in the capabilities of these integrated circuits. On the other hand, they produce a large amount of heat [1]. A microchannel heat sink is deemed to be one of the effective heat dissipation devices used for electronic cooling. However, its basic capabilities proved to be insufficient to cool down modern electronic chips using common coolants (Air and water). Nanofluids were introduced to elevate the cooling capabilities of the microchannel heat sinks. Lee et al. [2] showed that the shape and size of the nanoparticles contribute to the enhancement of the overall performance of the nanofluids. Xuan and Li [3] studied the effects of using different nanoparticles on the cooling performance of nanofluids. They showed that copper particles have a stronger effect than the metal oxide particles. Xue [4] analytical work showed that the carbon nanotubes had the best thermal conductivity compared to other nanofluids used in his work. In the past few years, several studies have been conducted to explore the genuine capabilities of using nanofluids in electronic cooling 
systems. Lee and Mudawar [5] in their landmark study investigated experimentally the effect of using nanofluid in both single-phase and two-phase flows. They used $\mathrm{Al}_{2} \mathrm{O}_{3}-\mathrm{H}_{2} \mathrm{O}$ as a cooling fluid. Their experiment showed that using nanofluids in two-phase flow state leads to catastrophic results because of passages blockage. As for the single-phase, they have reported that the improvement in the thermal performance was on the account of high pumping power requirement. Mohammed et al. [6] employed a hybrid analysis scheme to investigate the overall performance of a nanofluid $\left(\mathrm{Al}_{2} \mathrm{O}_{3}-\mathrm{H}_{2} \mathrm{O}\right)$ cooled microchannel heat sink under laminar flow condition. The performance of the system has been tested for the different volume fraction of the nanofluid. The best performance was noticed when the volume fraction was (5\%). Meanwhile, $\mathrm{Li}$ and Kleinstreuer [7] tested the microchannel heat sink cooled by $\mathrm{CuO}-\mathrm{H}_{2} \mathrm{O}$ nanofluid with Entropy generation minimization method. Volume fractions of (1\% and $4 \%)$ were investigated under laminar flow condition. Their key find was that there is a range of Reynolds number where the system can demonstrate its best performance. Ijam and Saidur [8] used a thermal resistance model to analyze mini channel heat sink with two different nanofluids ( $\mathrm{SiC}-\mathrm{H}_{2} \mathrm{O}$ and $\mathrm{TiO}_{2}-\mathrm{H}_{2} \mathrm{O}$ ). Turbulent flow condition was assumed and the system's performance was tested for different volume fractions $(0.8 \%, 1.6 \%, 2.4 \%, 3.2 \%$, and $4 \%)$. The optimized result revealed that $\mathrm{TiO}_{2}-\mathrm{H}_{2} \mathrm{O}$ exceeded $\mathrm{SiC}-\mathrm{H}_{2} \mathrm{O}$ in terms of pumping power for a volume fraction of $4 \%$. Mohammed et al. [9] in their review article highlighted the drawbacks of using nanofluids. Passage clogging due to sedimentation and high pumping power requirement were among the most series issues of using nanofluids as coolants. It can be seen from the aforementioned literature that the vast majority of the nanofluids used, had water as a base fluid. This paper reports the optimization of a microchannel heat sink using a new nanofluid in an endeavor to overcome the drawback of high pumping power requirement. This new nanofluid uses liquid ammonia $\left(\mathrm{NH}_{3}\right)$ as a base fluid with alumina $\left(\mathrm{Al}_{2} \mathrm{O}_{3}\right)$ as nanoparticles. The employment of ammonia was to elevate the overall performance of the coolant. The selection of $\left(\mathrm{Al}_{2} \mathrm{O}_{3}\right)$ was considered because aluminum is well known for its resistant to the corrosive effect of ammonia. The optimization scheme developed by Ahmed et al. [10] to analyze the overall thermal and hydrodynamic performances of a rectangular microchannel heat sink will be used in this study. Modifications have been made to the analysis model by using effector algorithm namely, the Strength Pareto Evolutionary Algorithm (SPEA2).

\section{MATHEMATICAL MODELING}

The schematic diagram of the microchannel heat sink considered in this study is shown in Figure 1.

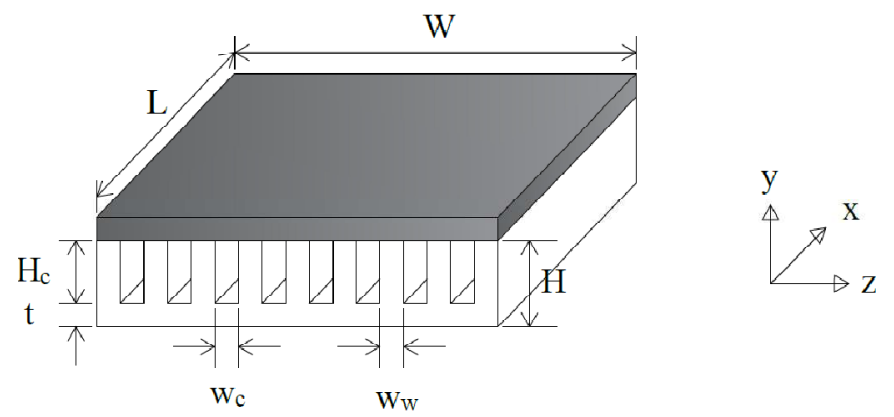

Figure 1: Schematic Drawing of the Microchannel Heat Sink Model

The proposed nanofluid namely $\mathrm{Al}_{2} \mathrm{O}_{3}-\mathrm{NH}_{3}$ with a volume fraction of $1 \%, 3 \%$, and $5 \%$ is employed. The thermophysical properties of $\mathrm{Al}_{2} \mathrm{O}_{3}-\mathrm{NH}_{3}, \mathrm{SiC}-\mathrm{H}_{2} \mathrm{O}, \mathrm{TiO}_{2}-\mathrm{H}_{2} \mathrm{O}$, and $\mathrm{Al}_{2} \mathrm{O}_{3}-\mathrm{H}_{2} \mathrm{O}$ are calculated based on the following equations [11-14] ( $n$ is assumed to be equal to 3 ). 


$$
\begin{aligned}
& \rho_{n f}=(1+\phi) \rho_{f}+\phi \rho_{p} \\
& \mu_{n f}=\frac{1}{(1-\phi)^{2.5}} \mu_{f} \\
& (\rho C p)_{n f}=(1-\phi)(\rho C p)_{f}+\phi(\rho C p)_{p} \\
& k_{n f}=\frac{k_{p}+(n-1) k_{f}-(n-1) \phi\left(k_{f}-k_{p}\right)}{k_{p}+(n-1) k_{f}+\phi\left(k_{f}-k_{p}\right)} k_{f}
\end{aligned}
$$

The properties at $20^{\circ} \mathrm{C}$ of the base fluids (liquid ammonia and water) and the nanoparticles employed in the current study are taken from Lienhard [15] and tabulated in Table 1. In this study, the dimensions and the operating conditions employed by Tuckerman and Pease [16] are utilized and listed in Table 2. To facilitate the analysis, the following assumptions are made.

- The properties were assumed to be constant.

- The fluid was single-phase and incompressible.

- $\quad$ The flow was considered to be a laminar steady flow.

Table 1: Thermophysical Properties of the Base Fluid and Nanoparticles at $20^{\circ} \mathrm{C}$

\begin{tabular}{|l|c|c|c|c|c|}
\hline \multicolumn{1}{|c|}{ Properties } & $\mathbf{N H}_{\mathbf{3}}$ & $\mathbf{H}_{\mathbf{2}} \mathbf{O}$ & $\mathbf{A l}_{\mathbf{2}} \mathbf{O}_{\mathbf{3}}$ & $\mathbf{S i C}$ & $\mathbf{T i O}_{\mathbf{2}}$ \\
\hline Density, ${ }^{\rho} \mathrm{kg} / \mathrm{m}^{3}$ & 609 & 994.2 & 3970 & 3160 & 4157 \\
\hline Specific heat capacity, ${ }^{C p} \mathrm{~J} / \mathrm{kg}-{ }^{\mathrm{o}} \mathrm{K}$ & 4740 & 4178 & 765 & 675 & 710 \\
\hline Thermal conductivity, ${ }^{k} \mathrm{~W} / \mathrm{m}-{ }^{\circ} \mathrm{K}$ & 0.521 & 0.625 & 40 & 490 & 8.4 \\
\hline Viscosity, ${ }^{\mu} \mathrm{N} . \mathrm{s} / \mathrm{m}$ & $1.38 .10^{-4}$ & $7.25 .10^{-4}$ & ---- & ---- & ---- \\
\hline
\end{tabular}

Table 2: The Dimensions and Operating Conditions used in the Current Study

\begin{tabular}{|l|c|}
\hline \multicolumn{1}{|c|}{ Parameters } & Values \\
\hline Heat sink width, ${ }^{W} \mathrm{~m}$ & $1 \times 10^{-2}$ \\
\hline Heat sink length, $L_{\mathrm{m}}$ & $1 \times 10^{-2}$ \\
\hline Channel height, ${ }^{H} \mathrm{~m}$ & $320 \times 10^{-6}$ \\
\hline Substrate thickness, ${ }^{t} \mathrm{~m}$ & $213 \times 10^{-6}$ \\
\hline Volumetric flow rate, ${ }^{G} \mathrm{~m}^{3} / \mathrm{s}$ & $4.7 \times 10^{-6}$ \\
\hline
\end{tabular}

The overall thermal and hydrodynamic performances of the considered system are determined through the thermal resistance and pressure drop/pumping power. The total thermal resistance is assessed using the thermal resistance equation provided in [10].

$$
R_{\text {total }}=\frac{L}{C p_{n f} \mu_{n f}} \frac{2}{\operatorname{Re}} \frac{1+\beta}{1+\alpha}+\frac{1}{h_{a v}} \frac{1+\beta}{1+2 \alpha \eta}+\frac{t}{k_{h s}}
$$

The required pumping power to circulate the coolant in the microchannel heat sink system is evaluated using the following equations given by [10].

$$
\Delta p_{t o t}=f_{h s} \frac{(1+\alpha) L}{2 H_{c}} \rho_{n f} \frac{V_{m n f}^{2}}{2}+\left(1.79-2.23\left(\frac{1}{1+\beta}\right)+0.53\left(\frac{1}{1+\beta}\right)^{2}\right) \rho_{n f} \frac{V_{m n f}^{2}}{2}
$$




$$
P p=\Delta p_{t o t} \times G
$$

A closer look at Equations (5-7) shows that these performance functions (thermal resistance and pumping power) depend on two variables ( $\alpha$ and $\beta$ ) therefore, the system will be treated for optimization purposes as a multi-objective function with two design variables.

\subsection{Heat Transfer and Friction Factor Correlations}

The heat transfer and friction factor correlations are crucial factors that contribute to the accuracy and credibility of the optimization process. Therefore, the following correlations are selected:

$$
h_{a v}=2.253+8.164\left(\frac{\alpha}{\alpha+1}\right)^{1.5} \frac{k_{n f}}{D_{h}}
$$

Equation (8) is given by Kim and Kim [17] is for liquid flowing inside the rectangular microchannel.

$$
f=0.316 \operatorname{Re}^{-0.25}
$$

Equation (9) offered by Blasius [18] was selected due to the adequate accuracy of the equation when it was compared to the experimental results given in [19]. This equation can be used in both laminar and early stages of turbulent flows i.e, $3000<\operatorname{Re}<105$.

\section{OPTIMIZATION PROCEDURE}

The nature of the problem under hand possess multi-objective functions in nature. The first objective function is thermal resistance with pumping power being the other objective function. Two design variables were involved in the current analysis namely the channel aspect ratio $(\alpha)$ and the wall width to channel width ratio $(\beta)$ with their limits listed in Table 3. Accordingly, the optimization scheme employed in [19] is recalled to perform the optimization. The SPEA2 is used to generate the Pareto optimal front of the objective functions in which a trade-off ability is provided. This SPEA2 algorithm is shown to possess some preference on NSGA-II in the microchannel heat sink optimization [20]. A code is developed along with SPEA2 toolbox in MATLAB (R2015) to produce denser Pareto Optimal front and hence more choices will be offered to the designers to best suit their design requirements. Figure 2 shows the complete steps of the optimization process.

Table 3: Design Variables Limits

\begin{tabular}{|l|c|c|}
\hline \multirow{2}{*}{ Limits } & \multicolumn{2}{|c|}{ Design variables } \\
\cline { 2 - 3 } & $\alpha$ & $\beta$ \\
\hline Upper & 5 & 0.1 \\
\hline Lower & 1 & 0.01 \\
\hline
\end{tabular}




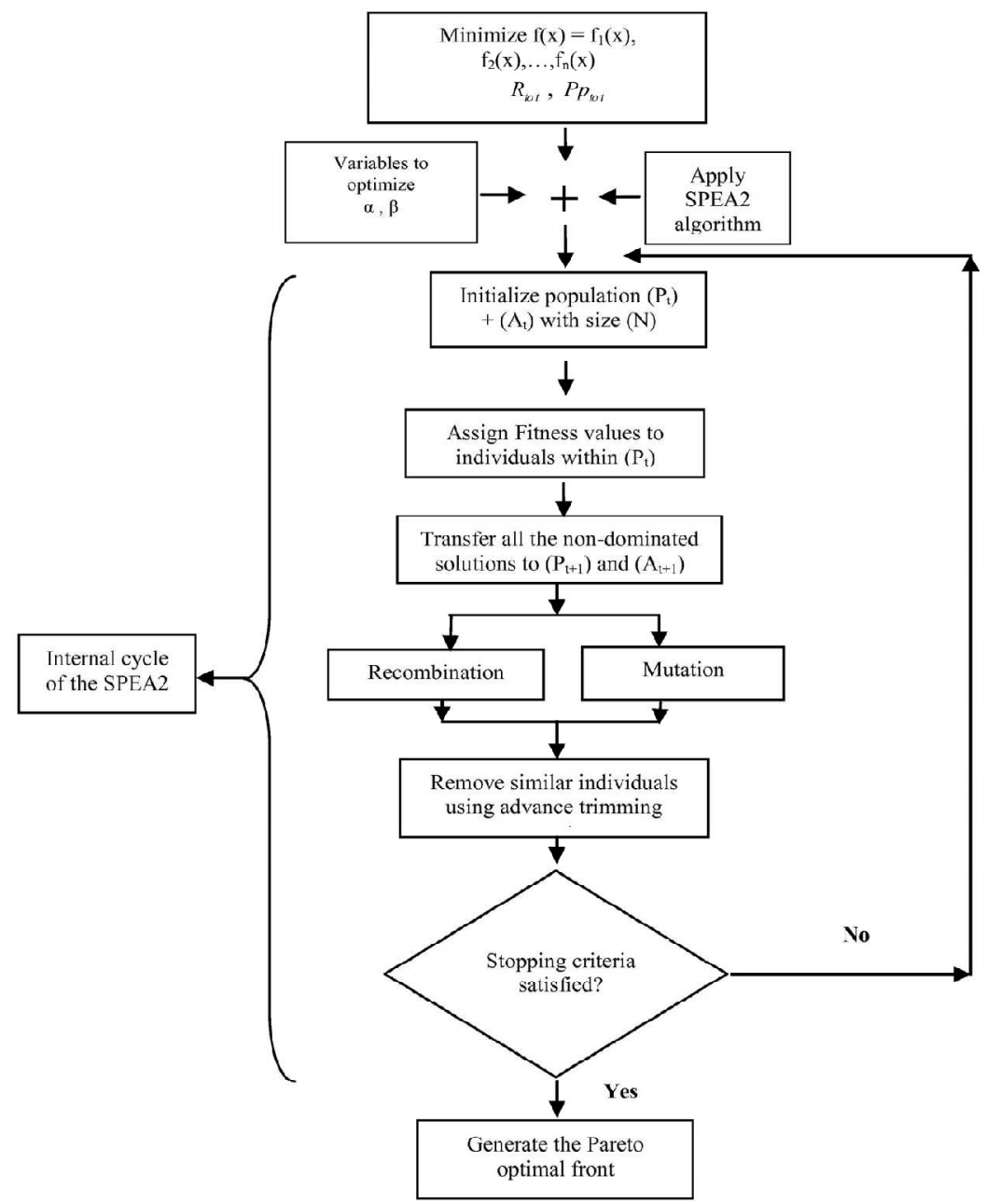

Figure 2: Optimization Procedure of SPEA2 (Adopted from [19])

\section{RESULTS AND DISCUSSIONS}

In this section, the overall performance of the nanofluid cooled $\left(\mathrm{Al}_{2} \mathrm{O}_{3}-\mathrm{NH}_{3}\right)$ microchannel heat sink is analyzed and optimized using three volume fractions $(1 \%, 3 \%$, and $5 \%$ ). The thermophysical properties of the nanofluid for different nanoparticle volume fractions are listed in Table 4. The main focus is on the pumping power required to achieve the minimum thermal resistance i.e., the best thermal performance. Firstly, the effect of different nanoparticle volume fractions on the overall performance is tested. Then, the performance of the $\mathrm{Al}_{2} \mathrm{O}_{3}-\mathrm{NH}_{3}$ is compared to other coolants. Furthermore, the effect of volumetric flow rate on the pumping power and thermal resistance is analyzed. Finally, the effect of different heat sink materials on the overall performance of the system is examined.

Table 4: Nanofluid Thermophysical Properties

\begin{tabular}{|c|c|c|c|}
\hline \multirow{2}{*}{ Properties } & \multicolumn{3}{|c|}{$\mathrm{Al}_{2} \mathrm{O}_{3}-\mathrm{NH}_{3}$} \\
\hline & $1 \%$ & $3 \%$ & $5 \%$ \\
\hline $\mathrm{kg} / \mathrm{m}^{3}$ & 642.6 & 709.8 & 777 \\
\hline$\mu_{n f} \times 10^{-4}$ N. s/m & 1.415 & 1.489 & 1.56 \\
\hline$C p_{n f} \quad \mathrm{~J} / \mathrm{kg}-{ }^{0} \mathrm{~K}$ & 4494.4 & 4073 & 3724.5 \\
\hline$k_{n f}$ & 0.536 & 0.567 & 0.6 \\
\hline
\end{tabular}




\subsection{Particle Volume Fraction}

The effects of different volume fractions on the pumping power and thermal resistance for three different nanofluids are depicted in Figures 3 and 4. It can clearly be seen that with the increase of the volume fraction, the required pumping power is increased while the thermal resistance is decreased. For volume fractions of 0.01, 0.03 and 0.05, the associated pumping power and thermal resistance are $0.128,0.138$ and $0.144 \mathrm{~W}, 0.073,0.07$ and $0.068 \mathrm{~K} / \mathrm{W}$, respectively. The refrigerant base nanofluid $\left(\mathrm{Al}_{2} \mathrm{O}_{3}-\mathrm{NH}_{3}\right)$ outperformed other water base nanofluids $\left(\mathrm{SiC}-\mathrm{H}_{2} \mathrm{O}\right.$ and $\left.\mathrm{TiO} \mathrm{O}_{2}-\mathrm{H}_{2} \mathrm{O}\right)$ in terms of pumping power by an appreciable factor. Furthermore, it can be inferred that the change in the volume fraction has a stronger effect on the pumping power than the thermal resistance. This behavior is expected because the increase in the nanoparticle volume fraction, increases the density of the nanofluid which consequently escalates the pressure drop of the system which ultimately increases the pumping power (Equations (6-7)). The overall result of this section is compatible with the fact that the higher pumping power is always accompanied by the lowest thermal resistance.

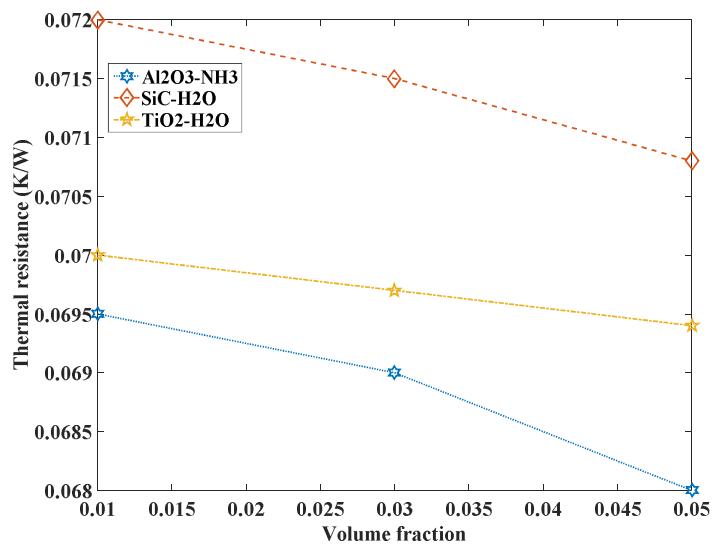

Figure 3: Particle Volume Fraction vs. Thermal Resistance

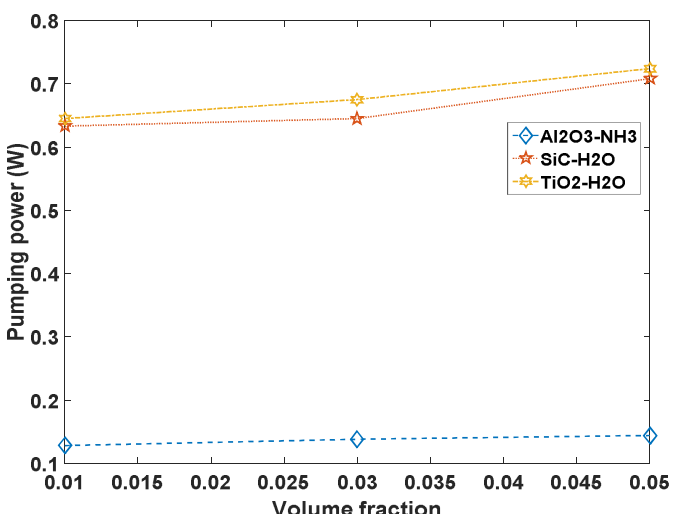

Figure 4: Particle Volume Fraction vs. Pumping Power

\subsection{Performance of the Coolant}

In this section, the performance of the $\mathrm{Al}_{2} \mathrm{O}_{3}-\mathrm{NH}_{3}$ is compared to water-base nanofluids namely, $\mathrm{Al}_{2} \mathrm{O}_{3}-\mathrm{H}_{2} \mathrm{O}$, $\mathrm{SiC}-\mathrm{H}_{2} \mathrm{O}, \mathrm{TiO}_{2}-\mathrm{H}_{2} \mathrm{O}$, and pure water. The thermophysical properties of the aforementioned Nanofluids (for the volume fraction of $5 \%$ ) and pure water at $20^{\circ} \mathrm{C}$ are tabulated in Table 5. The optimized results for the same operating conditions (Table 2) are listed in Table 6. The performance of the ammonia base nanofluid with $\left(\mathrm{Al}_{2} \mathrm{O}_{3}\right)$ nanoparticle was compared with the water base $\left(\mathrm{Al}_{2} \mathrm{O}_{3}\right)$ nanofluid and pure water and depicted in Figure 5. This was necessary to show the impact of usage of the refrigerant $\left(\mathrm{NH}_{3}\right)$ compared to water $\left(\mathrm{H}_{2} \mathrm{O}\right)$ when they used with the same nanoparticle $\left(\mathrm{Al}_{2} \mathrm{O}_{3}\right)$. 
Table 5: Nanofluids and Pure Water Thermophysical Properties

\begin{tabular}{|l|c|c|c|c|}
\hline Properties & $\mathbf{A l}_{2} \mathbf{O}_{3}-\mathbf{H}_{2} \mathbf{O}$ & $\mathbf{S i C}_{-} \mathbf{H}_{2} \mathbf{O}$ & $\mathbf{T i O}_{2}-\mathbf{H}_{2} \mathbf{O}$ & $\mathbf{H}_{2} \mathbf{O}$ \\
\hline Density, ${ }^{\rho} \mathrm{kg} / \mathrm{m}^{3}$ & 1146.79 & 1100 & 1150 & 998.2 \\
\hline Specific heat capacity, $C p \mathrm{~J} / \mathrm{kg}-^{-}{ }^{-} \mathrm{K}$ & 3590.55 & 3670 & 3550 & 4182 \\
\hline Thermal conductivity, $k \mathrm{~W} / \mathrm{m}-{ }^{0} \mathrm{~K}$ & 0.706 & 0.723 & 0.703 & 0.613 \\
\hline Viscosity, $\mu \mathrm{N} . \mathrm{s} / \mathrm{m}$ & 0.001128 & 0.000823 & 0.000823 & 0.001003 \\
\hline
\end{tabular}

Table 6: Optimized Results for Different Nanofluids

\begin{tabular}{|c|c|c|c|c|}
\hline \multirow{2}{*}{ Nanofluid } & \multicolumn{4}{|c|}{ Optimized Parameters } \\
\cline { 2 - 5 } & $\mathbf{R}(\mathbf{K} / \mathbf{W})$ & $\mathbf{P}(\mathbf{W})$ & $\boldsymbol{\alpha}$ & $\boldsymbol{\beta}$ \\
\hline $\mathrm{Al}_{2} \mathrm{O}_{3}-\mathrm{NH}_{3}$ & 0.068 & 0.144 & 4.987 & 0.015 \\
\hline $\mathrm{Al}_{2} \mathrm{O}_{3}-\mathrm{H}_{2} \mathrm{O}$ & 0.055 & 1.015 & 4.883 & 0.029 \\
\hline $\mathrm{SiC}^{-} \mathrm{H}_{2} \mathrm{O}$ & 0.0 .070 & 0.71 & 4.855 & 0.026 \\
\hline $\mathrm{TiO}_{2}-\mathrm{H}_{2} \mathrm{O}$ & 0.0695 & 0.72 & 4.882 & 0.025 \\
\hline $\mathrm{H}_{2} \mathrm{O}$ & 0.057 & 0.94 & 4.95 & 0.041 \\
\hline
\end{tabular}

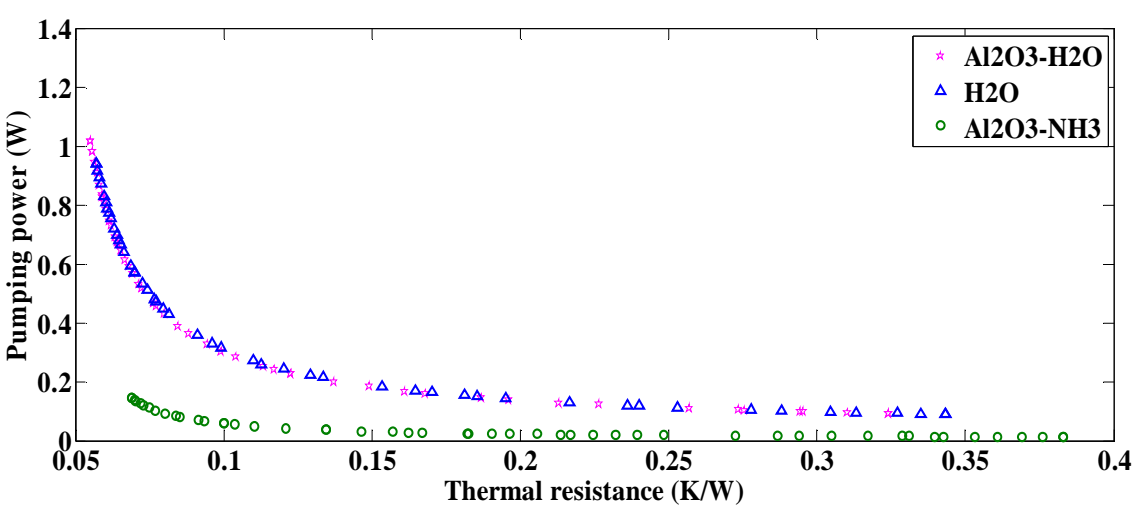

Figure 5: Pumping Power vs. Thermal Resistance for Different Coolants

It can be inferred from Figure 5 that $\mathrm{Al}_{2} \mathrm{O}_{3}-\mathrm{NH}_{3}$ significantly outperformed the other coolants $\left(\mathrm{Al}_{2} \mathrm{O}_{3}-\mathrm{H}_{2} \mathrm{O}\right.$ and $\mathrm{H}_{2} \mathrm{O}$ ) in terms of pumping power with slightly higher thermal resistance. This sacrifice in the thermal resistance can be justified by the huge gain in the pumping power which is greatly influences the size of the pump that will be used to pump the coolant. The comparison was made between these coolants because it shares the same nanoparticle. Furthermore, the ammonia base nanofluid also exceeded other water base nanofluids as it can be seen in Table 6 in terms of pumping power. The lower pumping power can be explained by the fact that the ammonia-base nanofluid posses lower density compared to the water-base nanofluid and pure water. However, the thermal resistance is higher for ammonia-base nanofluid because its properties (specific heat and thermal conductivity) that influence the thermal resistance are smaller compared to other coolants. Furthermore, the optimized results from Table 6 shows that using the ammonia-base nanofluid provides thinner channel walls and hence lighter heat sink i.e., $0.916 \times 10^{-6}, 1.792 \times 10^{-6}$ and $2.5 \times 10^{-6} \mathrm{~m}$ for the $\mathrm{Al}_{2} \mathrm{O}_{3}-\mathrm{NH}_{3}, \mathrm{Al}_{2} \mathrm{O}_{3}-\mathrm{H}_{2} \mathrm{O}$, and $\mathrm{H}_{2} \mathrm{O}$, respectively.

\subsection{Volumetric Flow Rate}

The effects of different volumetric flow rates of the coolant on the pumping power and thermal resistance are plotted in Figure 6. All the properties and dimensions are taken from Table 2. The optimized results are listed in Table 7. Looking at the far left of Figure 5 and Table 7, it can clearly be seen that the increase in the volumetric flow rate, the pumping power increases, and the thermal resistance decreases. This is due to the increase in the volumetric flow rate decreases the capacitive thermal resistance (first term in Equation (5)) which eventually decreases the total thermal 
resistance. Furthermore, it can be inferred from Table 7 that there is an optimum operating point that where the channel wall thickness is at its optimum (minimum) value i.e., for $\mathrm{G}=8.6 \times 10^{-6} \mathrm{~m}^{3} / \mathrm{s}$, the channel wall thickness is $0.916 \times 10^{-6} \mathrm{~m}$. It is preferable from the author point of view that the design should be around this optimum point because it has a moderated pumping power demand and produced heat sink is lighter.

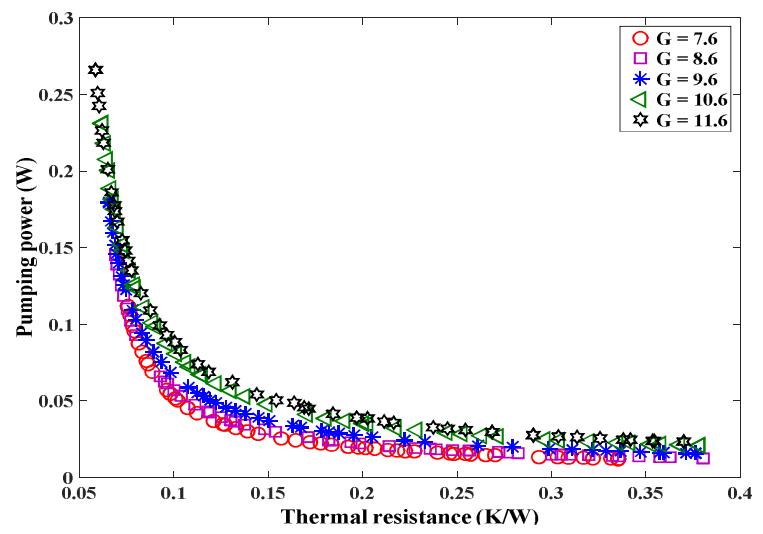

Figure 6: Pumping Power vs. Thermal Resistance for Different Flow Rates

Table 7: Optimized Results for Different Volumetric Flow Rates

\begin{tabular}{|c|c|c|c|c|}
\hline $\mathbf{G} \times \mathbf{1 0}^{-\mathbf{6}}\left(\mathbf{m}^{\mathbf{3}} / \mathbf{s}\right)$ & $\mathbf{R}(\mathbf{K} / \mathbf{W})$ & $\mathbf{P}(\mathbf{W})$ & $\boldsymbol{\alpha}$ & $\boldsymbol{\beta}$ \\
\hline 7.6 & 0.076 & 0.112 & 4.883 & 0.042 \\
\hline 8.6 & 0.068 & 0.144 & 4.987 & 0.015 \\
\hline 9.6 & 0.065 & 0.180 & 4.953 & 0.023 \\
\hline 10.6 & 0.062 & 0.231 & 4.978 & 0.058 \\
\hline 11.6 & 0.059 & 0.266 & 4.997 & 0.021 \\
\hline
\end{tabular}

\subsection{Heat Sink Material}

Total pumping power and thermal resistance for different heat sink materials are plotted in Figure 7. Two different heat sink materials namely, aluminum and silicon are selected with thermal conductivity values of 238 and 148 (W/ m-K) for aluminum and silicon, respectively. Resistivity to ammonia's corrosive effect was another selection criterion to select the materials. Higher thermal conductivity material offers lower thermal resistance for the same pumping power i.e., 0.066 and 0.068 for aluminum and silicon, respectively. This can be explained by the fact that higher thermal conductivity lowers the conductive thermal resistance (third term in Equation (5)) and hence lowers the total thermal resistance. Therefore, no additional pumping power is required.

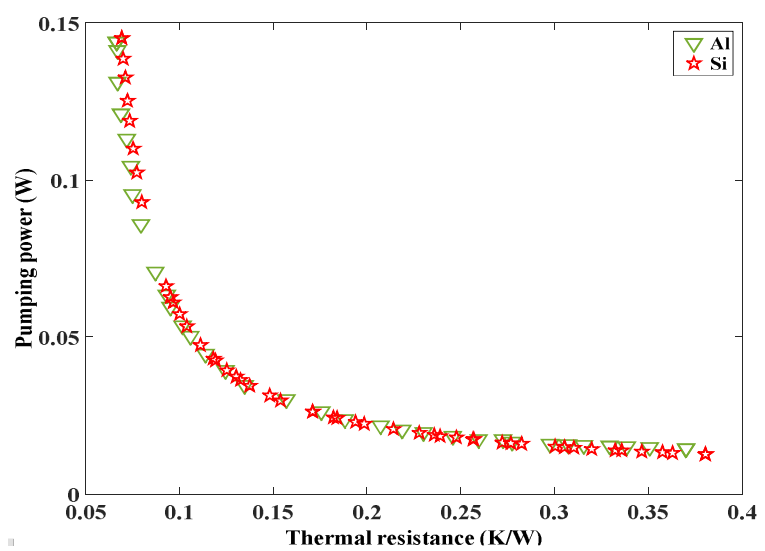

Figure 7: Pumping Power vs. Thermal Resistance for Different Heat Sink Materials 


\section{CONCLUSIONS}

Thermal and hydrodynamic performance of an ammonia-base nanofluid $\left(\mathrm{Al}_{2} \mathrm{O}_{3}-\mathrm{NH}_{3}\right)$ cooled microchannel heat sink was analytically studied. One of the very effective algorithms was employed to obtain highly accurate results namely, the Improved Pareto Evolutionary Algorithm (SPEA2). The main focus was on the required pumping power to circulate the coolant in the microchannel heat sink system. The effects of different parameters on the overall thermal resistance and pumping power were analyzed and discussed. It was found that $\mathrm{Al}_{2} \mathrm{O}_{3}-\mathrm{NH}_{3}$ outperformed (lower than) other coolants $\left(\mathrm{Al}_{2} \mathrm{O}_{3}-\mathrm{H}_{2} \mathrm{O}, \mathrm{SiC}-\mathrm{H}_{2} \mathrm{O}, \mathrm{TiO}_{2}-\mathrm{H}_{2} \mathrm{O}\right.$, and $\left.\mathrm{H}_{2} \mathrm{O}\right)$ in terms of the required pumping power by $\sim 85 \%$. An optimum point was found when different volumetric flow rates were used i.e., $G=8.6 \times 10^{-6} \mathrm{~m}^{3} / \mathrm{s}$, which resulted in a lighter heat sink. In addition, higher thermal conductivity material (aluminum) offers lower thermal resistance compared to silicon for the same pumping power i.e., $\mathrm{P}=0.144 \mathrm{~W}$. Finally, the noticeable results of this research may motivate other researchers to conduct more studies using the same nanofluid.

\section{REFERENCES}

1. A. M. Adham, N. M. Ghazali, R. Ahmad, Thermal and Hydrodynamic Analysis of Microchannel Heat Sinks: A Review, Renewable and Sustainable Energy Reviews, 21 (2013) 614-622.

2. S. Lee, S. U. S. Choi, S. Li, J. A. Eastman, Measuring Thermal Conductivity of Fluids Containing Oxide Nanoparticles, ASME Journal of Heat Transfer, 121 (1999) 280-289.

3. Y. Xuan, Q. Li, Heat Transfer Enhancement of Nanofluids, International Journal of Heat and Fluid Flow, 21 (2000) 58-64.

4. Q. -Z. Xue, Model for Effective Thermal Conductivity of Nanofluids, Phys. Lett., Vol. A 307, pp. 313-317, 2003.

5. J. Lee, I. Mudawar, Assessment of the Effectiveness of Nanofluids for Single-Phase and Two-Phase Heat Transfer in Microchannels, International Journal Heat and Mass Transfer, 50 (2007) 452-463.

6. H. A. Mohammed, P. Gunnasegaran, N. H. Shuaib, Heat Transfer in Rectangular Microchannels Heat Sink Using Nanofluids, International Communication in Heat and Mass Transfer, 37 (2010) 1496-1503.

7. J. Li, C. Kleinstreuer, Entropy Generation Analysis for Nanofluid Flow in Microchannels, ASME Journal of Heat Transfer, 131 (2010) 122401-1-122401-8.

8. A. Ijam, R. Saidur, Nanofluid as a Coolant for Electronic Devices (Cooling of Electronic Devices), Applied Thermal Engineering, 32 (2012) 76-82.

9. Saha, Satyajit., \& Bera, S. R. (2013). Growth and characterization of CdTe nanostructures grown by chemical reduction route. Int J Metall Mat Sci Eng (IJMMSE), 3(1), 37-40.

10. H. A. Mohammed, G. Bhaskaran, N. H. Shuaib, R. Saidur, Heat Transfer and Fluid Flow Characteristics in Microchannels Heat Exchanger Using Nanofluids: A Review, Renewable and Sustainable Energy Reviews, 15 (2011) 1502-1512.

11. A. M. Adham, N. M. Ghazali, R. Ahmad, Optimization of NanoFluid-Cooled Microchannel Heat Sink, THERMAL SCIENCE, 20 (2016) 109-118.

12. D. A. Drew, S. L. Passman, Theory of Multicomponents Fluids, (Springer. Berlin, 2003).

13. H. C. Brinkman, The Viscosity of Concentrated Suspensions and Solutions, Journal of Chemical Physics, 20 (1952) $571-581$.

14. S. M. Yang, W. Q. Tao, Heat Transfer, (3rd edition, Higher education press, Beijing, China, 1998). 
15. R. L. Hamilton, O. K. Crosser, Thermal Conductivity of Heterogeneous Two-Components Systems, Industrial and Engineering Chemistry Fundamentals, 1 (1962) 182-191.

16. J. H. Lienhard IV, J. H. Lienhard V, Heat Transfer Textbook, (3rd edition, Phlogiston press, Cambridge Massachusetts, USA, 2008).

17. D. B. Tuckerman, R. F. W. Pease, High Performance Heat Sinking for VLSI, IEEE Electr. DEV. Lett, 2 (1981) 126-129.

18. S. J. Kim, D. Kim, Forced Convection in Microstructures for Electronic Equipment Cooling, ASME Journal of Heat Transfer, 121 (1999) 639-645.

19. H. Blasius, Grenzschichten in Flussigkeiten mit kleiner Reibung (German), Z. Math. Phys. 56 (1908) 1-37.B.

20. N. Kumar, S. S. Sonawane, S. H. Sonawane, Experimental study of thermal conductivity, heat transfer and friction factor of Al2O3 based nanofluid, International Communications in Heat and Mass Transfer 9 (2018) 1-10.

21. Rashid, F., Dawood, K., \& Hashim, Ahmed. (2014). Maximizing of solar absorption by (TiO2-water) nanofluid with glass mixture. International Journal of Research in Engineering \& Technology, 2, 87-90.

22. A. M. Adham, N. M. Ghazali, R. Ahmad, Performance Optimization of a Microchannel Heat Sink Using the Improved Strength Pareto Evolutionary Algorithm (SPEA2), Journal of Engineering Thermophysics, 24 (2015) 86-100.

23. A. M. Adham, N. M. Ghazali, R. Ahmad, Multi-objective Optimization Algorithms for Microchannel Heat Sink, Contemporary Challenges \& Solutions in Applied AI, SCI489 (2013) 169-174. 
